\title{
Effect of light on ultrastructure of chloroplasts and post-storage performance of Hydrangea macrophylla (Hydrangeaceae)
}

\author{
G. PELLEGRINO + , I. PERROTTA, and A.M. PALERMO \\ Department of Biology, Ecology and Earth Science, University of Calabria, 87036 Rende (CS), Italy
}

\begin{abstract}
The plants of Hydrangea are normally stored in dark conditions during shipping. In this study, Hydrangea macrophylla plants were stored for $0-15 \mathrm{~d}$ in light or darkness to evaluate the effect of the storage duration and condition on the chloroplast ultrastructure and chlorophyll $(\mathrm{Chl})$ content. Moreover, the plants stored in the dark were transferred to a growth chamber to evaluate their resilience. The plants stored in the dark showed a decrease in number of chloroplasts and starch grains, and granal and intergranal thylakoids with irregular morphology. On the contrary, the same leaves showed an increase of the number of plastoglubuli. The $\mathrm{Chl}$ content of the plants remained relatively unchanged during storage under light conditions, but decreased under dark conditions. Transplanted plants stored for 3-9 d in the dark showed normal oval-shape chloroplasts and orderly and dense thylakoids. On the contrary, the plants stored for 12 or $15 \mathrm{~d}$ in the dark did not recover normal leaf phenotypes or chloroplast ultrastructure. This study demonstrated that long duration of darkness altered irreversibly the chloroplast ultrastructure and the photosynthetic ability and affected the regrowth potential of Hydrangea macrophylla plants.
\end{abstract}

Additional key words: electron microscopy; leaf morphology; hortensia; organelle; stress recovery.

The genus Hydrangea L. includes at least 23 species, hybrids and cultivars, which can be deciduous or evergreen shrubs, small trees or climbers (McClintock 1957). The genus is divided into the sections Hydrangea and Cornidia. Species of section Hydrangea are regarded as one of the most important ornamental plants in Europe. The taxa currently found in the trade in Europe include H. arborescens L., H. macrophylla (Thunb.), H. paniculata Siebold, and H. quercifolia Bartram. Hydrangeas commonly produced commercially are deciduous shrubs, selected for their showy inflorescence. H. macrophylla is one of the most popular species in the genus. It is native to East Asia (Japan and Korea), introduced into England by Joseph Banks in 1789, and nowadays numerous cultivars with a wide spectrum of flower color have been bred through selection and intraspecific crosses (van Gelderen and van Gelderen 2004). The floral display of Hydrangea is largely due to sterile florets, grouped into large rounded corymbs or conical panicles, and ranges from white to shades of pink, purple, and blue. Fertile flowers are generally inconspicuous. Plants usually grow $80-150 \mathrm{~cm}$ high, but can grow to $3 \mathrm{~m}$ with width equal to or greater than the plant height. This ornamental plant is commonly known as hortensia.

To ensure an adequate supply of seedlings, the plants are normally stored in dark conditions when waiting for optimal weather for transplantation or during shipping. The availability of light affects the metabolism of plants (Javanmardi and Emami 2013, Kwack et al. 2016). In particular, the darkness modifies the process of photosynthesis and triggers many modifications regarding the Chl content and the ultrastructure of chloroplasts (Pfeiffer and Krupinska 2005, Lütz and Engel 2007). Indeed, photosynthesis is among the plant cell functions that are highly sensitive to any type of changes, such as water deficit (Pinheiro and Chaves 2011), high temperature (Song et al. 2014), UV radiation (Fonini et al. 2017), and mainly the low light intensity (Darko et al. 2014, Ruban 2015, Wang et al. 2015, Mathur et al. 2018). The quantity and quality of light affects the photosynthetic apparatus of plants during storage and during the subsequent recovery period (Duan et al. 2014). Chloroplasts are main organelles of photosynthesis and their morphology is closely linked to photosynthesis. A decrease in photosynthetic activity involves an alteration of ultrastructure of chloroplasts (Cortleven and Schmülling 2015, Wang et al. 2016). The morphological variations concern the chloroplast shape and size and the internal structure of the chloroplast that includes thylakoid membranes and grana (Shimoni et al. 2005, Fu et al. 2013, Han et al. 2017). The chloroplasts are also the site of starch formation and accumulation. Environmental factors such

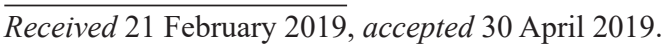

+Corresponding author; e-mail: giuseppe.pellegrino@unical.it

Abbreviations: Chl - chlorophyll; UV - ultraviolet. 
as light availability influence the metabolism of starch grains, modifying their shape and size (Gregoriou et al. 2007). Moreover, leaves exposed to high light intensities show a higher Chl content than plants under low light intensities (Fu et al. 2010).

Few studies have been carried out on the effects of storage and the subsequent recovery period on photosynthetic apparatus of ornamental plants and on anatomical and morphological ultrastructure modification (Duan et al. 2014). The present knowledge on the effects of irradiance on chloroplast structure and associated photosynthetic capacity of Hydrangea is still insufficient. For this reason, we performed experiments to quantify the effects of storage from 0 to $15 \mathrm{~d}$ in light or darkness at $15^{\circ} \mathrm{C}$, and the subsequent recovery, on the chloroplast ultrastructure and photosynthetic activity of Hydrangea macrophylla plants. The aim of the present study was to identify the effect of the storage duration and conditions (light or darkness) on the chloroplast ultrastructure and Chl content. Accurate assessing of these effects is essential for maintaining Hydrangea plants quality during storage and for improving the capacity of photosynthetic recovery after removal from storage.

All the following experiments were conducted in the greenhouse and laboratories at University of Calabria, Rende, Italy $\left(39^{\circ} 19^{\prime} \mathrm{N}, 16^{\circ} 11^{\prime} \mathrm{E}\right)$. Uniform cuttings were taken from mother plants of Hydrangea macrophylla (Thunb.) and propagated in plug trays with a mixture of peat and perlite $(2: 1, \mathrm{v} / \mathrm{v})$ in a greenhouse under a natural 12-h photoperiod with day/night temperature of $25 / 18^{\circ} \mathrm{C}$ and $70 \%$ relative humidity. All plants were well watered. About $20 \mathrm{~d}$ later, uniform rooted seedlings were transplanted into 2-L pots containing an organic seed substrate consisting of peat moss, perlite, and vermiculite $(7: 3: 1, \mathrm{v} / \mathrm{v} / \mathrm{v})$ and transferred in two growth chambers.

Each growth chamber contained ten Hydrangea plants. There were two light treatments, the seedlings were stored for $15 \mathrm{~d}$ in darkness or under light intensity (PPFD) in the range of $300-400 \mu \mathrm{mol}\left(\right.$ photon) $\mathrm{m}^{-2} \mathrm{~s}^{-1}$. The light was provided by cool white light lamps (Philips LIFEMAX, TLD Royal Philips Electronics, Amsterdam, The Netherlands) positioned approximately $30 \mathrm{~cm}$ above the seedling canopy. Every 2 d, the seedling trays were irrigated with the same nutrient solution for $10 \mathrm{~min}$. The seedlings were sampled just before the start of storage $(0 \mathrm{~d})$ and then every $3 \mathrm{~d}$. Measurements were replicated three times, making three measurements on different individuals in each experiment. After storage in light or darkness for $3,6,9,12$ or $15 \mathrm{~d}$, the plants from each treatment were transferred to a growth chamber under normal culture conditions $\left(25 / 18^{\circ} \mathrm{C}\right.$ day/night temperature, PPFD of $300 \mu \mathrm{mol} \mathrm{m} \mathrm{m}^{-2} \mathrm{~s}^{-1}$ ] for $10 \mathrm{~d}$ and sampled again.

For transmission electron microscopy (TEM) the middle part of the leaves without the midrib was used and cut into small pieces $(3 \times 3 \mathrm{~mm})$. Samples of leaves were fixed in $2.5 \%(\mathrm{v} / \mathrm{v})$ glutaraldehyde in $0.1 \mathrm{M}$ phosphate buffer at $\mathrm{pH} 7.4$ for $2 \mathrm{~d}$ at $4^{\circ} \mathrm{C}$ and post-fixed in $1 \%(\mathrm{w} / \mathrm{v})$ $\mathrm{OsO}_{4}$ in $0.1 \mathrm{M}$ phosphate buffer at $\mathrm{pH} 7.4$ for $2 \mathrm{~h}$ at $4^{\circ} \mathrm{C}$. The samples were subsequently dehydrated through an acetone series. They were then embedded in Spurr's resin. Ultra-thin sections ( $60 \mathrm{~nm}$ ) were cut using diamond knives (Diatome Ultra $45^{\circ}$ ) and a Leica Ultracat UCT ultramicrotome (EM UC6, Leica, Germany). Longitudinal and transverse sections were collected on coated copper grids, stained for $6 \mathrm{~min}$ in uranyl acetate, post-stained for $6 \mathrm{~min}$ in lead citrate (Reynolds 1963), and examined using a Zeiss EM10 transmission electron microscope at an accelerating voltage of $60 \mathrm{kV}$. The photographs were used for the quantification of chloroplasts and for the quantitative measurements of organelles, such as thylakoids, starch grains, and plastoglobuli. Four photographs for each treatment were covered by a gridded $(0.5 \times 0.5 \mathrm{~cm})$ transparent film. Each organelle at a grid intersection was counted and its percentage as a total of intersections over the whole chloroplast surface was calculated (Toth 1982, Savidis et al. 1989). Results were expressed as mean \pm standard error. Data were subjected to the analysis of variance (ANOVA) and Duncan's multiple range tests were employed to detect differences between means (with $P$ set at 0.05 ). All the statistical analysis was performed using SPSS 13.0 for Windows (SPSS, Chicago, IL, USA).

The middle part of the leaves without the midrib was used to measure $\mathrm{Chl}$ content. Chl $a$ and $\mathrm{Chl} b$ were quantified spectrophotometrically, following the protocol developed by Sims and Gamon (2002). Leaves were grinded in an acetone:Tris $(80: 20, \mathrm{v} / \mathrm{v})$ buffer solution. The Chl content was determined by measuring the absorbance at wavelengths of 537, 663, and $647 \mathrm{~nm}$ using a UV-Vis spectrophotometer (SuperScan3, Varian Techtron, Mulgrave, Australia), and using the following formulas: Chl $a=0.01373 \mathrm{~A}_{663}-0.000897 \mathrm{~A}_{537}-0.003046 \mathrm{~A}_{647}$; Chl $b=0.02405 \mathrm{~A}_{647}-0.004305 \mathrm{~A}_{537}-0.005507 \mathrm{~A}_{663}$.

The dark conditions significantly changed the internal structure of mesophyll cells, in terms of the number of chloroplasts, starch grains, grana, and stroma lamellae structure, and osmiophilic granules (Fig. 1), as well as in terms of chloroplasts and organelles size (Table 1S, supple$m e n t)$. No differences in mesophyll cell were observed between the light and dark treatments until the $6^{\text {th }} d$ of storage. Then the internal structure of leaves was significantly changed, especially after treatments for 12 and $15 \mathrm{~d}$.

The leaf mesophyll of plants exposed to light and of the plants stored in dark conditions for 3 and $6 \mathrm{~d}$ was clearly differentiated into palisade and spongy layers, while plants stored in dark conditions for more than $6 \mathrm{~d}$ exhibited the palisade parenchyma containing larger intercellular spaces and palisade cells did not show the typical rectangular shape. The number of chloroplasts in palisade and spongy cells was reduced significantly under dark stress. The more severe the stress, the lesser number of chloroplasts. Indeed, in leaves stored under dark conditions for 12 and $15 \mathrm{~d}$, the number of chloroplasts per cell profile significantly decreased (Fig. 1). The chloroplasts became round in shape and also their length and width decreased, with an increased thickness and an increased number of granal thylakoids (Table 1S). Moreover, while granal and intergranal thylakoids of the chloroplasts in leaves under light were usually distinguished, those of leaves stored 

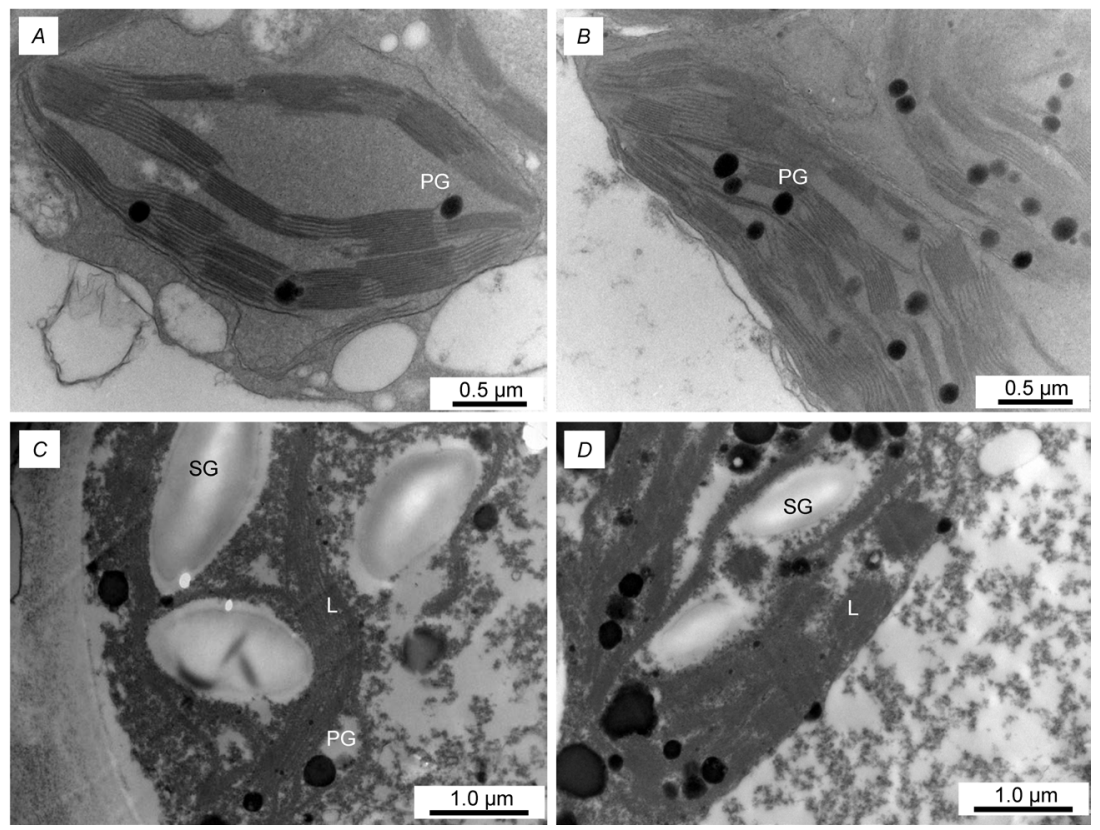

Fig. 1. A comparison of the ultrastructure of chloroplasts in Hydrangea macrophylla plants after $3 \mathrm{~d}(A, C)$ and $12 \mathrm{~d}(B, D)$ of storage in the dark. $\mathrm{L}$ - lamellae, $\mathrm{PL}$ - plastoglobuli, $\mathrm{SG}$ - starch grain. Bar: $500 \mathrm{~nm}(A, B), 1 \mu \mathrm{m}$ $(C, D)$.

in dark conditions appeared dilated and with irregular morphology (Fig. 1S, supplement). The number of starch grains per chloroplast decreased significantly and their length and width decreased significantly, too.

In the chloroplasts, small plastoglobuli were observed between the thylakoids (Fig. 1) and their number seemed to increase in the chloroplasts under dark conditions (Table 1S).

Ten days after transplantation following dark storage for 3,6 , or $9 \mathrm{~d}$, the chloroplasts in the leaves returned to a normal oval shape, and the thylakoids were arranged orderly and dense. The number of chloroplasts returned to normal conditions and the starch grains accumulated. On the contrary, the plants, which were stored for 12 or $15 \mathrm{~d}$ in the dark, did not recover to their normal leaf phenotypes or chloroplast ultrastructure after transplantation, showing numerous plastoglobuli and disordered grana thylakoids in the chloroplasts.

Leaves of Hydrangea macrophylla under natural conditions showed three times higher concentration of $\mathrm{Chl} a$ $\left(85.6 \mathrm{mg} \mathrm{g}^{-1}\right)$ than that of $\mathrm{Chl} b\left(30.82 \mathrm{mg} \mathrm{g}^{-1}\right)$. The Chl content remained relatively unchanged during storage under light conditions, showing relatively higher amount of Chl $a\left(86.1-85.6 \mathrm{mg} \mathrm{g}^{-1}\right)$ and $\mathrm{Chl} b$, but decreased under dark conditions. Indeed, the Chl content of the leaves decreased with the duration of the storage period under dark conditions and significantly decreased after $9 \mathrm{~d}$ of storage in the dark (Fig. 2). The Chl content of plants transplanted after storage for 3-9 $\mathrm{d}$ in the darkness recovered to the level of plants stored under light. The plants transplanted after longer time in the darkness (12 or $15 \mathrm{~d}$ ) showed the lower Chl content than that of light-stored plants (Fig. 2).

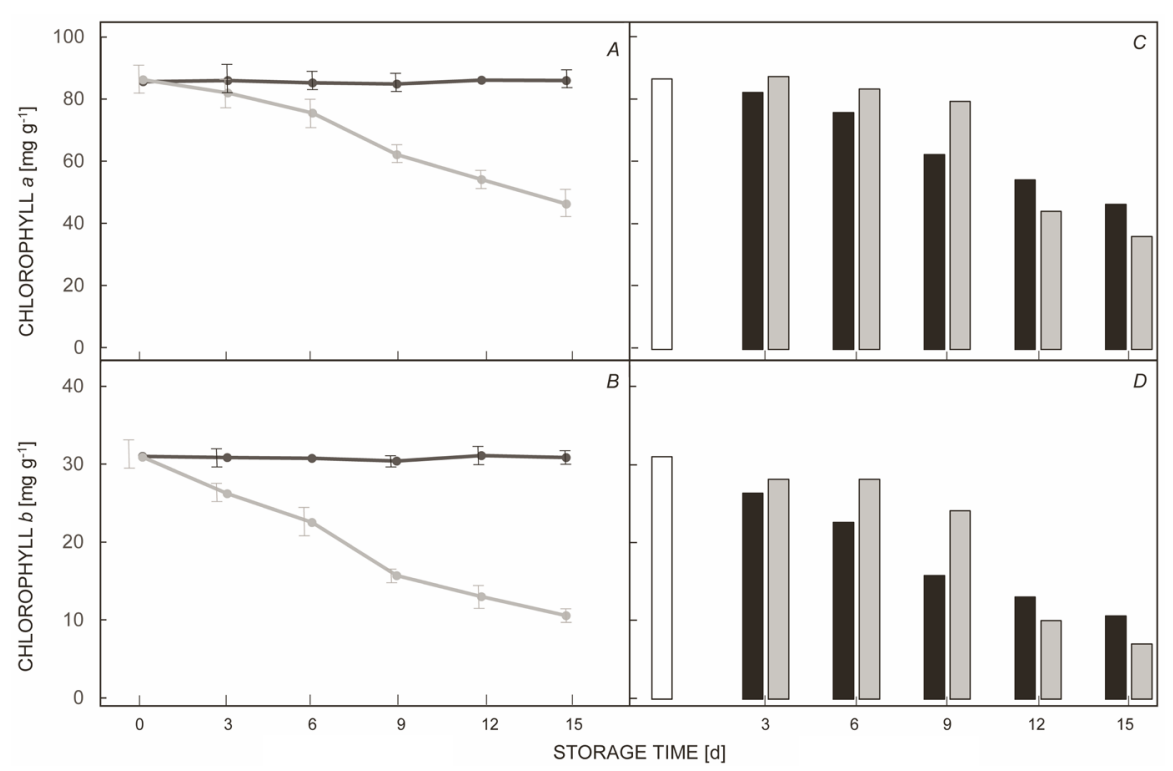

Fig. 2. The chlorophyll $a(A)$ and $b(B)$ content in the leaves of Hydrangea macrophylla plants stored in the light (black line) or in the dark (gray line), and the chlorophyll $a(C)$ and $b(D)$ content of plants transplanted for $10 \mathrm{~d}$ (grey bar) after being stored in the dark for 3-15 d (black bar). The control (white bar) was taken from leaves that have never been stored. Data represent the average \pm SE of three replicates. 
The changes in chloroplasts were typical for plants stressed by extreme temperatures, low light, saline stress, and water stress (Fu et al. 2011, Pinheiro and Chaves 2011, Song et al. 2014). The Chl content is a critical determinant for the rate of photosynthesis (Niachiro et al. 2001, Long et al. 2006). In this study, the light-kept plants showed the higher Chl content during storage than those that were stored in darkness. During the dark storage, Chl in a leaf is susceptible to degradation, involving alteration of the chloroplast ultrastructure. The considerable alteration of the chloroplast ultrastructure in dark-stored leaves might be the result of their rapid loss of Chl. Leaves of lightkept plants showed chloroplasts with typical structural characteristics. The inner membrane system was typically structured, composed of relatively high grana (18-25 thylakoids), well-developed stromal thylakoids, and granal and intergranal thylakoids usually distinguished. Grana were stacked in parallel with the prevailing plane of thylakoid lamellae. On the contrary, we highlighted that dark storage significantly modified both the Chl content and the chloroplast ultrastructure of the leaves, confirming that chloroplast development depends on light, and light affects chloroplast structure and photosynthetic changes in plants (Duan et al. 2014, Mathur et al. 2018). Indeed, leaves of Hydrangea macrophylla stored for a long time (12 or $15 \mathrm{~d})$ in dark conditions showed drastic modifications of the chloroplasts, which were smaller in size and present in smaller numbers (Fig. 1). In addition, another atypical feature was the location of single, peripheral stromal thylakoids that were randomly oriented in the peristromium and granal thylakoids disordered with a low stacking degree. These characteristics are interpreted as destructive changes in response to the darkness conditions in agreement with previous studies in which chloroplast deformations are described (Młodzianowski and Ponitka 1973, Bondada and Oosterhuis 2002, Stoyanova-Koleva et al. 2005).

The lower starch accumulation in the chloroplasts and the reduction of starch size in plants stored in the dark (Table 1S) is an indication of the lower photosynthetic capacity of their leaves. The decrease in the number of starch grains (approx. 50\%) is mainly because starch grains act as a reserve of carbohydrates are consumed during the dark when photosynthesis is not possible (Scofield et al. 2009, Scialdone and Howard 2015). Similar results were reported for other species, such as in leaves of Olea europaea (Gregoriou et al. 2007).

We observed the increase in the number and size of plastoglobuli in dark-kept plants. It is assumed that the formation of plastoglobuli is associated with the degradation of thylakoids (Smart 1994). Plastoglobuli play an important role in the synthesis and recycling of lipophilic products, have a function in storage of thylakoid components, such as plastohydroquinone and tocopherol, in response to the oxidative stresses of the cell (MunnéBosch et al. 2001).

The plants stored under dark conditions for $12-15 \mathrm{~d}$ did not exhibit recovery of their photosynthetic ability after transplanting, and they showed deterioration of leaves. The effects of storage under dark conditions on chloroplasts were similar to those of senescence. Indeed, leaf senescence can be induced by internal and external signals. Among the external factors, the main ones are extreme heat or cold and light availability (Thomas and Stoddart 1980). During leaf senescence, the first sign of senescence is a modification of chloroplasts, such as a decrease of Chl content, disorientation of the grana stacks, swelling of the thylakoids and an increase in number of enlarged plastoglobuli (Kutík et al. 2001). During the initial phase of leaf senescence, a degradation of $\mathrm{Chl}$ occurs, in a late step, chloroplasts are slowly converted to gerontoplasts (Parthier 1988, Wise and Hoober 2007). The conversion of a gerontoplast to a chloroplast is possible, but once the cell enters the terminal phase of senescence, it goes through cell death and therefore the development of gerontoplast from chloroplast becomes irreversible. In our case, the leaves of plants transplanted to light conditions after the long period of dark storage still exhibited modified ultrastructure with numerous plastoglobuli and disordered grana thylakoids in the chloroplasts. Contradictory data on the recovery of the chloroplast ultrastructure after light or dark storage can be found in the literature. Seedlings of watermelon, Citrullus lanatus, which were stored in the dark for $6 \mathrm{~d}$, did not recover their thylakoid structure $6 \mathrm{~d}$ after transplantation (Duan et al. 2014). On the contrary, leaves of Cucurbita pepo stored in the dark for $5 \mathrm{~d}$ showed normal chloroplasts $5 \mathrm{~d}$ after transplanting into light conditions (Ananieva et al. 2004). A comparative study on Larix decidua, Pinus sylvestris, and Picea abies showed that conifers need just $2 \mathrm{~d}$ of light to restore chloroplast ultrastructure in plants stored in the dark for two weeks (Walles and Hudák 1975).

This study demonstrated the effects of the storage duration and conditions (light or darkness) on the chloroplast ultrastructure and chlorophyll content in Hydrangea macrophylla plants. The plants stored in the light for 3-15 d exhibited a normal chloroplast ultrastructure with well-organized grana thylakoids and high value of chlorophyll content compared to the dark-stored plants.

The effects on the plants transferred to a growth chamber under normal culture conditions and sampled after $10 \mathrm{~d}$ depended on the duration of storage. Indeed, the plants that were stored in the darkness for 3-9 d showed a good capacity of resilience, while the plants stored for longer time (12-15 d) lost their ability to recover. Our study indicates that long duration of dark irreversibly altered the chloroplast ultrastructure and the photosynthetic apparatus and affected the regrowth potential of Hydrangea macrophylla plants. These data need to be taken into account when the plants are subjected to too long transport which can lower the quality of the product for sale.

\section{References}

Ananieva K., Malbeck J., Kamínek M., Staden J.: Changes in endogenous cytokinin levels in cotyledons of Cucurbita pepo (zucchini) during natural and dark-induced senescence.Physiol. Plantarum 122: 133-142, 2004.

Bondada B.R., Oosterhuis D.: Ontogenic changes in epicuticular wax and chloroplast integrity of a cotton (Gossypium hirsutum L.) leaf. - Photosynthetica 40: 431-436, 2002. 
Cortleven A., Schmülling T.: Regulation of chloroplast development and function by cytokinin. - J. Exp. Bot. 66: 4999-5013, 2015.

Darko E., Heydarizadeh P., Schoefs B., Sabzalian M.R.: Photosynthesis under artificial light: the shift in primary and secondary metabolism. - Philos. T. Roy. Soc. B 369: $20130243,2014$.

Duan Q., Jiang W. Ding M., Lin Y., Huang D.: Light affects the chloroplast ultrastructure and poststorage photosynthetic performance of watermelon (Citrullus lanatus) plug seedlings. - PLoS ONE 9: e111165, 2014.

Fonini A.M., Barufi J.B., Schmidt E.C., Rodrigues A.C., Randi A.M.: Leaf anatomy and photosynthetic efficiency of Acrostichum danaeifolium after UV radiation. Photosynthetica 55: 401-410, 2017.

$\mathrm{Fu}$ Q.S., Zhao B., Wang X.W. et al.: The responses ofmorphological trait, leaf ultrastructure, photosynthetic and biochemical performance of tomato to differential light availabilities. - J. Integr. Agr. 10: 1887-1897, 2011.

Fu Q.S., Zhao B., Wang Y.J. et al.: Stomatal development and associated photosynthetic performance of capsicum in response to differential light availabilities. - Photosynthetica 48: 189-198, 2010.

Fu Q.S., Yang R.C., Wang H.S. et al.: Leaf morphological and ultrastructural performance of eggplant (Solanum melongena L.) in response to water stress. - Photosynthetica 51: 109-114, 2013.

Gregoriou K., Pontikis K., Vemmos S.: Effects of reduced irradiance on leaf morphology, photosynthetic capacity, and fruit yield in olive (Olea europaea L.). - Photosynthetica 45: 172-181, 2007

Han S., Chen S.M., Song A.P. et al.: Photosynthetic responses of Chrysanthemum morifolium to growth irradiance: morphology, anatomy and chloroplast ultrastructure. Photosynthetica 55: 184-192, 2017.

Javanmardi J., Emami S.: Application of sucrose on tomato seedlings improves transplant quality, crop establishment, cold and dark hardiness. - Adv. Hort. Sci. 27: 122-126, 2013.

Kutík J., Holá D., Vičánková A. et al.: The heterogeneity of structural and functional photosynthetic characteristics of mesophyll chloroplasts in various parts of mature or senescing leaf blade of two maize (Zea mays L.) genotypes. Photosynthetica 39: 497-506, 2001.

Kwack Y., Lee J.-H., Chun C.: Proper period and temperature for transportation of cucumber and tomato transplants. - Hortic. Environ. Biote. 57: 554-559, 2016.

Long S.P., Zhu X.G., Naidu S.L., Ort D.R.: Can improvement in photosynthesis increase crop yields? - Plant Cell Environ. 29: 315-330, 2006.

Lütz C., Engel L.: Changes in chloroplast ultrastructure in some high-alpine plants: Adaptation to metabolic demands and climate? - Protoplasma 231: 183-192, 2007.

Mathur S., Jain L., Jajoo A.: Photosynthetic efficiency in sun and shade plants. - Photosynthetica 56: 354-365, 2018.

McClintock E.: A monograph of the genus Hydrangea. - Proc. Calif. Acad. Sci. 24: 147-256, 1957.

Młodzianowski F., Ponitka A.: Ultrastructural changes of chloroplasts in detached parsley leaves yellowing in darkness and the influence of kinetin on that process. - Z. Pflanzenphysiol. 69: 13-25, 1973.

Munné-Bosch S.: The role of $\alpha$-tocopherol in plant stress tolerance. - J. Plant Physiol. 162: 743-748, 2005.

Niachiro J.M., Briggs K.G., Hoddinott J., Johnson-Flanagan A.M.:
Chlorophyll content, chlorophyll fluorescence and water deficit in Spring wheat. - Cereal Res. Commun. 29: 135-142, 2001.

Parthier B.: Gerontoplasts - the yellow end in the ontogenesis of chloroplasts. - Endocyt. Cell Res. 5: 163-190, 1988.

Pfeiffer S., Krupinska K.: New insights in thylakoid membrane organization. - Plant Cell. Physiol. 46: 1443-1451, 2005.

Pinheiro C., Chaves M.M.: Photosynthesis and drought: can we make metabolic connections from available data? - J. Exp. Bot. 62: 869-882, 2011.

Reynolds E.S.: The use of lead citrate at high $\mathrm{pH}$ as an electronopaque stain in electron microscopy. - J. Cell Biol. 17: 208-212, 1963.

Ruban A.V.: Evolution under the sun: optimizing light harvesting in photosynthesis. - J. Exp. Bot. 66: 7-23, 2015.

Savidis, T.H., Eleftheriou, P.E., Tsekos, I.: The floral nectarines of Hibiscus rosa-sinensis. III. A morphometric and ultrastructural approach. - Nordic J. Bot. 9: 63-71, 1989.

Scialdone A., Howard M.: How plants manage food reserves at night: quantitative models and open questions. - Front. Plant Sci. 6: 204, 2015.

Scofield G.N., Ruuska S.A., Aoki N. et al.: Starch storage in the stems of wheat plants: localization and temporal changes. Ann. Bot. 103: 859-868, 2009.

Shimoni E., Rav-Hon O., Ohad I. et al.: Three-dimensional organization of higher-plant chloroplast thylakoid membranes revealed by electron tomography. - Plant Cell 17: 2580-2586, 2005.

Sims D.A., Gamon J.A.: Relationships between leaf pigment content and spectral reflectance across a wide range of species, leaf structures and developmental stages. - Remote Sens. Environ. 81: 337-354, 2002.

Smart C.M.: Gene expression during leaf senescence. - New Phytol. 126: 419-448, 1994.

Song Y., Chen Q., Ci D. et al.: Effects of high temperature on photosynthesis and related gene expression in poplar. - BMC Plant Biol. 14: 111, 2014.

Stoyanova-Koleva D., Edreva A., Velikova V., Gurel A.: Effect of reddening of cotton (Gossypium hirsutum L.) leaves on the ultrastructure of mesophyll cells. - Photosynthetica 43: 313-316, 2005.

Thomas H., Stoddart J.L.: Leaf senescence. - Ann. Rev. Plant Physio. 31: 83-111, 1980.

Toth R.: An introduction to morphometric cytology and its application to botanical research. - Amer. J. Bot. 69: 16941706, 1982.

van Gelderen C.J., van Gelderen D.M.: Encyclopedia of Hydrangeas. Pp. 280. Timber Press, Portland 2004.

Walles B., Hudák J.: A comparative study of chloroplast morphogenesis in seedlings of some conifers (Larix decidua, Pinus sylvestris and Picea abies). - Stud. Forest. Suec. 127: 1-22, 1975.

Wang X.Y., Xu X.M., Cui J.: The importance of blue light for leaf areaexpansion, development of photosynthetic apparatus, and chloroplastultrastructure of Cucumis sativus grown under weak light. - Photosynthetica 53: 213-222, 2015.

Wang S., Wang X., Shi X. et al.: Red and blue lights significantly affect photosynthetic properties and ultrastructure of mesophyll cells in senescing grape leaves. - Hortic. Plant J. 2: 82-90, 2016.

Wise R., Hoober J.: The Structure and Function of Plastids. Pp. 575. Springer, Dordrecht 2007.

(C) The authors. This is an open access article distributed under the terms of the Creative Commons BY-NC-ND Licence. 